\title{
РАЗЛИЧИЯ В ВОСПРИЯТИИ ЦВЕТОВЫХ ЭТАЛОНОВ В ПОЛЬСКОМ И РУССКОМ ЯЗЫКАХ
}

\author{
DIFFERENCES IN THE PERCEPTION OF COLOR PATTERNS \\ IN POLISH AND RUSSIAN LANGUAGES
}

\begin{abstract}
АНДЖЕЙ НАРЛОХ
ABSTRACT. The author of the article tries to present the semantic differences in the perception of color patterns based on the example of two languages - Polish and Russian. Contemporary dictionaries as well as the psycholinguistic experiment that was conducted among Polish and Russian respondents provided a basis for the research. The author demonstrates the conceptual diversity of ways in which colors are perceived in the two languages. The differences in color semantics that are presented here are determined by different color patterns, different stages of the development of the color pattern and different perceptions of colors in these languages. It is difficult to classify some of the names of dominant colors. Neither do the respondents provide explicit answers, which makes it difficult to precisely define the name of a given color.
\end{abstract}

Andrzej Narloch, Uniwersytet im. Adama Mickiewicza w Poznaniu, Poznań - Polska.

Проблематика изучения лексики цвета широко представлена в ряде лингвистических работ. Цветовая лексика описывалась с различных сторон - словообразовательной, семантической, психолингвистической, когнитивной и др. Настоящая статья посвящена исследованию семантических различий в восприятии цветовых образцов (эталонов) на примере двух близкородственных языков - русского и польского. Материальной базой послужили данные современных толковых словарей, а также психологический эксперимент, проведенный на группе польских и русских информантов ${ }^{1}$.

Восприятие человеком окружающего мира непосредственно связано с процессом категоризации. Согласно теории лингвистической относительности (центрального понятия этнолингвистики), каждый язык располагает индивидуальной сеткой деления и систематизации мира, по-своему концептуализует внеязыковую реальность. В связи с этим

${ }^{1}$ В данном эксперименте испытуемые должны были отнести представленные им прилагательные цвета к одному из основных цветообозначений, т.е. к 12 цветообозначениям в русском языке и 11 цветообозначениям в польском. 
один и тот же фрагмент действительности в разных языках может представлять собой адекватную, но не совпадающую концептуальную схему. Эффектом такой дифференцированной концептуализации в группе цветовой лексики являются, например, лексемы изикламеновый и cyklamenowy, которые восходят к греч. kykláminos и называют род многолетних трав семейства первоцветных (алыпийская фиалка). Русское ццикламеновый, согласно словарной дефиниции, - это 'цве́та цикламена; розово-сиреневый' (БТСРЯ, 1463). Основой доминанты данной лексемы является сиреневый цвет, т.е. светло-фиолетовый оттенок². Таким образом, колоратив концептуализуется русскоговорящими как оттенок фиолетового. Опираясь на данные польских толковых словарей, мы должны отнести прилагательное cyklamenowy к доминанте розового цвета, ср.: 'w kolorze cyklamenów, czyli różowy z odcieniem fioletowym' (PSWP, 7, 331). Доминантный розовый приводят также другие польские словари, которые фиксируют существительное cyklamen в значении цвета: 'kolor różowy o odcieniu fioletowym' (SJPBr, 98), (USJP, 1: 493). Один из польских словарей не исключает даже и доминанту красного, cp.: 'kolor czerwony lub różowy o odcieniu fioletowym' (MSJP, 103).

Различия в категоризации касаются и других цветообозначений, например польского marengo и русского маренго. Оба колоратива появились в результате семантического развития существительного, называющего один из сортов меланжевой шерстяной ткани маренго. Данные колоративы происходят от ит. marengo 'цвет маренго', что восходит к названию деревни Маренго (ит. Marengo), расположенной в Северной Италии, где впервые начала производиться ткань подобного цвета. При слове marengo польские лексикографические источники указывают доминанту szary (рус. серыи): 'ciemnoszary kolor - taki jak tkaniny marengo' (SWJP, 496), 'ciemnoszary, taki jak tkaniny marengo' (PSWP, 20: 248) ${ }^{3}$. Русские словари чаще всего указывают на чёрный цвет, ср. маренго - это 'ткань черного цвета с белыми нитями' (НСРЯ, 1: 834), 'черный с сероватым отливом (о цвете)' (НСРЯ, 2: 229). Несомненно, такие различия в категоризации предопределяются природой ниток (волокон) ткани, так как такая ткань представляет собой смесь белых, серых и черных волокон и поэтому может в большей степени напоминать или серый, или черный оттенок.

Семантические различия в значении цветообозначений так или иначе связаны с их эталонами, которые легли в основу номинацион-

\footnotetext{
2 Согласно лексикографическим данным, сиреневый толкуется как 'бледно-лиловый, цвета сирени' (БТСРЯ, 1180), (СРЯ, 4: 98).

3 Один лишь словарь SJPD в лексеме marengo видит доминанту чёрный: 'czarna, wełniana tkanina przerabiana białą lub szarą nitką; kolor tej tkaniny' (SJPD, 4: 455).
} 
ных процессов. Одной из причин появления расхождений в значении лексем, имеющих общий эталон, является то, что в основе колоратива лежит многоцветный эталон. В каждом языке эталоном цвета может стать иная часть или стадия развития (функционирования) цветового образца. Примером такой неустойчивости, вызванной выбором различных составных частей эталона, является в польском языке прилагательное migdatowy. Цветовым образцом для польской лексемы (на основании дефиниции, приведенной в словаре SJPD) оказались, с одной стороны, семена миндаля 4 . С другой стороны, словари SJPSz и SWJP допускают возможность ссылки как на семена миндаля, так и на его цветки, которые имеют розовый цвет (SJPSz, 2: 169), (SWJP, 520). В связи с этим И. Беляева не исключает возможности семантической трансформации польского колоратива и развития у лексемы другого значения цвета 5 . Нелишным будет сослаться также на мнение польских респондентов, которые в большинстве случаев определяли migdałowy не как оттенок коричневого или розового цветов, а как оттенок белого цвета! Видимо, в основу категоризации в данном случае лег не внешний вид семян миндаля или цвет розовых лепестков, а внутренняя часть семян (косточки), которая имеет молочно-белый цвет.

В русском языке эталоном цвета миндальный стали только цветки миндаля, ср. дефиницию 'розовый, такой, как цветки миндаля' (СРЯ, 2: 272). Следовательно, семантика польского колоратива migdatowy не покрывается с его русским эквивалентом, у которого не наблюдается процесс развития других значений цвета так, как это наблюдается в польском языке.

Отличия в восприятии цветового эталона могут быть вызваны также его новизной, что является причиной его колористической нестабильности. Кроме того, сам эталон цвета может оказаться нестабильным с цветовой стороны и меняться в рамках определенного цветового диапазона. Актуализация семантики наступает уже на уровне конкретного употребления или контекста. На основе всей массы разноцветных образцов преобладает определенный цветовой тип, который становится доминирующим. Поэтому словари, фиксируя такую лексему, или не приводят ее конкретное цветовое значение, или ссылаются только на цвет эталона без фиксации столь важной для его осмысления цветовой доминанты. Примером такого прилагательного может стать польское jagodowy. Лексемy jagodowy не фиксируют современные словари, но в значении цвета ее употребляют в речи, определяя, в частности, цвет артефактов (в сфере дизайна, одежды, прикладного искусства). На

${ }^{4}$ I. B j e 1 a j e v a, Niepodstawowe nazwy barw w języku polskim, czeskim, rosyjskim i ukrainskim, Warszawa 2005, c. 62.

5 Там же. 
основе наглядных материалов, доступных автору, удалось установить, что колоратив выражает или фиолетовый, или синий оттенок. Респонденты указывали прежде всего на доминанту фиолетового оттенка. Цветовым образцом для синего стал цвет плодов черники обыкновенной (лат. Vaccínium myrtíllus), ср.: Ciepła bielizna w pięknym, jagodowym kolorze (по Интернету). В польском языке прилагательное jagodowy понимается также как светло-фиолетовый с розовым оттенком. Об этом свидетельствуют многие факты. Например, в мире моды и дизайна (одежда, обувь) под цветом jagodowy понимают именно промежуточный цвет между фиолетовым и розовым. В таком случае в основу значения цвета лег не цвет плодов черники, а скорее всего цвет продуктов, приготавливаемых из черники, таких как мороженое или коктейли.

Что касается русского ягодный, то лексему трудно найти в современных словарях в значении цвета ${ }^{6}$. Однако она все чаще появляется в значении цвета и понимается в основном как оттенок фиолетового. Следует отметить, что в русском языке значительная часть респондентов указывала также на доминанту красного. Такой результат обусловлен диапазоном понятий ягоды/jagody в обоих языках. В русском языке лексема ягода традиционно понимается шире, как 'небольшой сочный плод кустарников, полукустарников, кустарничков и травянистых растений' (ТСРЯ, 916), напр.: ягоды крыжовника, малины, черники, клюкъы. Поэтому ассоциации лексемы ягодный также с красно-розовыми оттенками вполне естественны, в отличие от польского jagoda, где преобладает традиционная ассоциация с плодом черники обыкновенной (польск. borówka czarna). Значение польского колоратива jagodowy в большей степени соответствует русскому черничный 'темно-синий' .

Как уже указывалось, расхождения в категоризации являются результатом нестабильности эталона, вызванной различиными этапами цветовой стадии эталона. Данный фактор предопределяет семантические различия на межъязыковом уровне. Асимметричность значения, обусловленная стадией развития образца, находит свое выражение в польском groszkowy и русском гороховый. Согласно словарным дефинициям, гороховый следует причислить к доминанте желтого, ср.: 'имеющий цвет гороха; серовато-желтый с зеленым оттенком' (НСРЯ, 1: 330), (БТСРЯ, 221), (СРЯ, 1: 336). Такая трактовка связывает цвет гороховый с цветом сваренного гороха7. Между тем И. Беляева утверждает, что

\footnotetext{
${ }^{6}$ Словарные материалы лексему ягодный в значении цвета фиксируют в составе сложного прилагательного темно-ягодный, см.: Новое в русской лексике. Словарные материалы - 1982, под ред. Н.3. Котеловой, Москва 1986, с. 200.

7 V. P e t r u n i č e v a, Paleta barw w jezzyku rosyjskim (o przymiotnikowych nazwach barw), [в:] Studia z semantyki porównawczej: nazwy barw, nazwy wymiarów, predykaty mentalne, red. R. Grzegorczykowa, K. Waszakowa, cz. I, Warszawa 2000, c. 56.
} 
эталоном русского эквивалента стали высушенные семена гороха ${ }^{8}$. Дополнительную трудность в определении точного оттенка вводит Толковый словарь русского языка (ред. С.И. Ожегов и Н.Ю. Шведова), который локализирует гороховыи в доминанту серого, ср.: 'зеленовато-серый с желтым оттенком, цвета зрелого гороха' (ТСРЯ, 140). Такие различия в значении не выявляются в польском языке. Большинство словарей наименование groszkowy регистрирует в значении 'светло-зеленый' (PSWP, 13: 91), (SWJP, 289), (SJPBr, 217). В качестве цветового эталона выступает свежий зеленый горох, а не - как в русском - высушенные семена гороха или гороховый суп.

Некоторые затруднения появляются при характеристике ияета чайной розы. Первоначально определение чайная роза возникло не на основе сходства с цветом чая, а от аромата цветков, напоминающих аромат свежезаваренного чая. Растение чайная роза (лат. Rosa odorata) имеет в основном лепестки розовой, светло-кремовой и желтой окраски. Поэтому значение иъвета чайной розы закрепилось за кремово-желтыми оттенками. По словарным источникам, данный колоратив выражает светлый оттенок желтого цвета9.

Однако на основании наглядных материалов, доступных автору, удалось определить, что параллельно желтой доминанте это цветообозначение понимается также как светло-розовый оттенок, в частности в сфере моды, в которой цвет одежды определяют именно этим цветообозначением: жакет извета чайной розы, свадебное платье извета чайной розы. Таким образом, возможно, что имеем дело с семантическим сдвигом у этого цветообозначения, видимо, под влиянием слова роза и его сильной связи с розовым цветом.

Несколько иное значение несет прилагательное чайный. Как считает И. Беляева, чайный в значении цвета употребляется только в названном уже устойчивом обороте - изъета чайной розы. Тем не менее в современном русском языке можно отметить и самостоятельное упоребление прилагательного чайный в значении цвета. Укажем только, что карие глаза определяют также как глаза чайного иъвета, т.е. коричневого цвета (БТСРЯ, 418), (НСРЯ, 1: 649). В сфере моды широко известен колоратив чайный, который, в частности, маркирует цвет одежды - безрукавка чайного иъета, платье чайного иъвета (по Интернету). Эквивалентом русского чайный является польское herbaciany. Подобно русской, польская лексема употребляется в устойчивом обороте róża herbaciana, т.е. определяет желтый цвет одного из сортов розы. Как правильно замечает И. Беля-

8 I. В j e l a j e v a, указ. соч., с. 92.

9 Доминанту желтого цвета сохраняет также цвет кузова автомобилей - чайная роза 'светло-желтый'. Краской данного цвета покрывают автомобили марки Лада, [электронный ресурс:] http://avtozerkala.com/benefits/colore (25.08.2012). 
ева, на примере этой лексемы можно наблюдать процесс семантической трансформации ${ }^{10}$. Колоратив herbaciany в современном польском языке употребляется самостоятельно, без слова róża. Словари фиксируют лексему в значении 'цвет слабого чая' (польск. 'kolor słabej herbaty', SJPSz, 1: 735), не эксплицируя конкретную цветовую доминанту. Мы сослались на ответы респондентов, которые дали основания отнести данный цвет к оттенкам коричневого цвета, так как подавляющее большинство из них определили herbaciany как оттенок именно коричневого ${ }^{11}$. На современном этапе развития системы цветообозначений herbaciany маркирует чаще всего одежду, материалы, ткани.

Некоторые трудности возникают при попытке определить цветовую доминанту прилагательных musztardowy и горчичный. Обе лексемы имеют общий эталон - горчииу (польск. musztarda). Как правило, горчица имеет разный цвет, варьирующий в пределах желто-коричневых оттенков, о чем свидетельствуют дефиниции: 'ostra przyprawa w postaci półpłynnej żółtobrązowej masy, sporządzona ze zmielonych nasion gorczycy, z dodatkiem octu winnego, korzeni, czasem chrzanu, używana do mięsa, sosów itp.' (USJP, 2: 747). Не разъясняют вопроса также словарные статьи. Например, словари польского языка фиксируют следующие значения: 'taki, którego składnikiem jest musztarda, lub który ma smak, kolor musztardy' (SWJP, 545), 'taki, który ma związek z musztardą; taki, który zawiera musztardę: kolor musztardowy' (PSWP, 22: 140), 'przym. od musztarda: Sos musztardowy. Kolor musztardowy' (SJPSz, 2: 231). В большинстве примеров название цвета musztardowy появляется в экземплификационной части без конкретной экспликации цветового значения. Поэтому необходимым оказалось сослаться на мнение информантов, две трети которых определили musztardowy как оттенок желтого цвета12.

Подобные отличия наблюдаются при попытке отнести к одной из цветовых доминант прилагательное горчичный. Например, В.К. Харченко и И. Беляева относят его к доминанте желтого ${ }^{13}$. Р.М. Фрумкина

${ }^{10}$ I. В j e 1 a j e v a, указ. соч., с. 55.

11 Словарные дефиниции толкуют herbaciany как цвет слабого чая, что могло стать поводом его отнесения к доминанте желтого. Возможно, что все чаще этот цвет ассоциируется не с цветом слабого чая, а крепкого, т.е. по цвету напоминающего коричневыи. Таким образом, не исключено, что перед нами семантический сдвиг значения слова herbaciany - от сферы желтых оттенков в сторону коричневых. Однако окончательное решение данного вопроса требует еще дальнейших психолингвистических исследований.

12 Следует отметить, что четверть респондентов считает musztardowy оттенком коричневого цвета.

13 B.К. Х а р ч е н к о, Словарь иявета: реальное, потенцииальное, авторское. Свыше 4000 слов в 8000 контекстах, Москва 2009, с. 103; I. В ј е 1 а ј е v а, указ. соч., с. 92. 
включает колоратив в группу зеленых оттенков 14 , а лексикографические источники помещают горчичный в спектре коричневого, ср.: 'желтовато-коричневый, цвета горчицы' (ТСРЯ, 140), '[...] желтовато-коричневый’ (НСРЯ, 1: 330), ‘имеющий цвет горчицы, желтовато-коричневый' (БТСРЯ, 221). Носители русского языка также единогласно не указали на превосходство одной из доминант, разделив свои мнения по половине. Таким образом, данный колоратив относится к одному из наиболее трудно определяемых цветообозначений в семантическом плане.

Рассмотрим другие пары цветообозначений, между которыми выявляются различия в цвете. Такие различия в восприятии цвета касаются колоративов, в основу которых лег цвет кожи человека. Цвет кожи человека обусловливается комплексом фенотипических наследственных признаков и связан с географическим местом проживания. Для русских и поляков данный фактор не имеет применения. Тем не менее имеются некоторые расхождения в категоризации этого цвета. Цвет кожи в польском языке воспринимается поляками, скорее всего, как бледный оттенок коричневого с розовым оттенком, ср.: cielisty 'mający barwę ciała ludzkiego; kremowy, jasnobeżowy z odcieniem bladoróżowym' (SJPSz, 1: 296), 'taki, który naśladuje barwę ciała ludzkiego; kremowy, jasnobeżowy z odcieniem bladoróżowym' (PSWP, 7: 196) ${ }^{15}$. Pусский эквивалент телесный указывает также на натуральный цвет кожи человека. Однако между обоими языками намечаются некоторые расхождения в семантике. В русском доминантную позицию занимает розовый, ср.: 'цветом напоминающий тело человека; бледно-розовый' (НСРЯ, 2: 757), ‘бледно-розовый, цвета тела' (ТСРЯ, 792). Следует отметить, что некоторые словари приводят довольно трудные для восприятия дефиниции значения, ср.: 'желтовато-белый с розоватым оттенком' (СРЯ, 4: 348), (БТСРЯ, 1312). Поэтому, на наш взгляд, особенно трудно эксплицировать семантику цвета кожи человека.

Подобные семантические различия регистрируют словари обоих языков между эквивалентами оливковый и oliwkowy. Польские словари определяют oliwkowy как оттенок зеленого, дополнительно подчеркивая в словарных дефинициях информацию о незрелых плодах, ср. 'mający kolor niedojrzałego owocu oliwki, żółtawozielony, szarozielony lub żółtobrązowy' (SJPD, 5: 972), (SJPSz, 2: 515). Если придерживаться лексикографических данных, то русское оливковый следует отнести к коричневым оттенкам, что подтверждает словарь под ред. А.П. Евгеньевой,

14 Р.М. Ф р у м к и н а, Цвет, смысл, сходство. Аспекты лингвистического анализа, Москва 1984, с. 62.

15 Стоит добавить, что Stownik języka polskiego под ред. В. Дорошевского указывает на доминанту розового цвета, ср.: 'mający barwę ciała; bladoróżowy' (SJPD, 1: 975). 
толкуя оливковый как 'светло-коричневый с желтоватым или зеленоватым отливом' (СРЯ, 2: 615). Таким же образом объясняют слово Большой толковый словарь русского языка (БТСРЯ, 712) и И. Беляева' ${ }^{16}$. Несомненно, доминанту коричневого несет слово, определяя цвет кожи человека. Если же лексема оливковыи характеризует другие объекты окружающей действительности, то ее следует отнести к доминанте зелёного. Это подтверждает и В.К. Харченко, который определяет данный цвет как 'серовато-зеленый с легкой прожелтью' (СЦ, 287). Также Каталог названий ивета в русском языке помещает оливковый цвет в группу зеленых оттенков, ср.: 'цвета спелых оливок или пареной травы, желто-зеленый' $(\mathrm{K}, 16)$. Следовательно, эталоном для цветообозначения стала зеленая разновидность плодов оливкового дерева.

Расхождения в семантике касаются также цвета земли. Цвет земли непосредственно обусловливается содержанием глины, минералов, горных пород в различном качестве и количестве, а также натуральных пигментов в почве. Поэтому в разных языках данный цвет может концептуализироваться по-разному. Р. Токарски в статье Biała brzoza, czarna ziemia, czyli o miejscu stereotypu w opisie jezyka ищет прототипический эталон для польского czarny, пытаясь найти его в слове ziemia. Автор ссылается на работу А. Вежбицкой, которая для английского brown (коричневый) определила прототипическое земля (the ground) ${ }^{17}$. Разноцветность земли отчетливо проявляется в терминах цвета из сферы живописи, которые определяют цвет земли, ср., например, сепия/sepia, умбра/итьrа, итальянская земля, земля Поциуоли, земля Сиены/zіетіа Siепу, кассельская земля/ziemia kasselska. В таком случае цвет земли непосредственно зависит от географического положения, т.е. связан с ее химической структурой. Как пишет Р. Токарски, „Perceptualna niestabilność barw gleby jest duża. Wszędzie tam, gdzie w ziemi występują związki metali, zwłaszcza żelaza, przybiera ona różne odcienie brązów i czerwieni. Udział gliny i piasku również powoduje zmienność jej naturalnego zabarwienia"18. Автор доказывает, что для польского czarny прототопическим является ziemia, базируясь на устоявшихся в польском языке фраземах и фразеологизмах ${ }^{19}$. А что говорят об этом словари польского

16 I. B j e 1 a j e v a, указ. соч., с. 96.

17 R. T o k a r s k i, Biała brzoza, czarna ziemia, czyli o miejscu stereotypu w opisie jezyka, [в:] Jezzyk a Kultura, t. 12: Stereotyp jako przedmiot lingwistyki. Teoria, metodologia, analizy empiryczne, red. J. Anusiewicz, J. Bartmiński, Wrocław 1998, c. 131.

18 Там же.

${ }^{19}$ Согласно исследованиям К. Вашаковой, для цвета сzarny прототипическим является пос, см.: K. W a s z a k o w a, Podstawowe nazwy barw $i$ ich prototypowe odniesienia. Metodologia opisu porównawczego, [в:] Studia z semantyki porównawczej..., указ. соч., c. 23. 
языка? Один из лексикографических источников толкует колоратив ziemisty (являющийся дериватом от ziemia) как 'o barwie skóry, cery ludzkiej: przypominający ziemię; blady z odcieniem brunatnoszarym': z. cera, twarz (SJPSz, 3: 1019). Несколько по-другому объясняет значение цветообозначения словарь PSWP: 'taki, którego kolor przypomina barwę ziemi, jest szary z brunatnym odcieniem lub czarnym odcieniem' (PSWP, 4: 320). Из представленного вытекает, что польское ziemisty концептуализируется как серый оттенок с коричневатыми или черными оттенками. Наличие серого оттенка, видимо, обусловливается его характеристикой цвета кожи. Кроме того, колоратив коннотирует также сему 'болезненый, нездоровый, невыразительный'.

В русском языковом ареале эквивалентом польской лексемы является землистый. Подобно ее польскому эквиваленту, она имеет ограниченную сочетаемость и маркирует цвет лица, ср.: 'серовато-бледный, напоминающий цвет земли (о цвете лица)' (ТСРЯ, 1: 607); 'серовато-бледный (о цвете лица, кожи человека)' (БТСРЯ, 363). Такой цвет приобретает лицо в основном в болезненном состоянии. Следовательно, землистый является одновременно индикатором эмоционально-физического состояния человека. Словарь извета, регистрируя данный цвет, приводит даже оговорку „о лище нездорового человека” 20 . Различия между обоими языками сводятся в основном к наличию в польском языке дополнительных сем 'черный' и 'коричневый'. Последняя сема выражается в прилагательном brunatny (см. словарные дефиниции польского ziemisty).

Остановимся еще на прилагательных стальной и stalowy. В большинстве прилагательных со значением цвета, образованных от названий металлов, колоративы обогащаются семой ‘блестящий'. Такая сема выделяется также в обоих указанных прилагательных. Однако между ними возникают различия в плане цветовой доминанты. Семантика русского стальной сосредоточивается вокруг доминанты серого цвета. Толковые словари объясняют лексему как 'имеющий цвет стали; серебристо-серый' (БТСРЯ, 1259), 'серебристо-серый' (ТСРЯ, 762). Приведем еще дефиницию из Словаря иъета В.К. Харченко: 'блещущий серый, холодным блеском похожий на сталь. Цвет воды в пасмурный день' (СЦ, 439). Автор обогащает семантику слова еще семой 'холодный'. Наличие в семантике цвета „температурной” семы несомненно обусловливается тем, что металл ассоциируется с чем-то прохладным, холодным. Поэтому именно такой колоратив используется для описания холодных природных объектов: стальная гладь моря (БТСРЯ, 1259) или: Могучий неухоженный лес, крепкие подосиновики, стальная вода озера, грозные север-

20 B.К. Х а р ч е н к о, указ. соч., с. 155. 
ные закаты...; Вместо белой пелены на месте моря видны голубовато-серые стальные поверхности воды (СЦ, 439). Таким образом, семантика русского цветообозначения не вызывает сомнений и разногласий. Что касается польского stalowy, то толкование значения колоратива не так просто. Руководствуясь польскими лексикографическими источниками, цвет stalowy следует отнести не к серым оттенкам, а к синим! Убедительным доказательством такого отнесения значения лексемы являются словарные дефиниции, ср.: 'mający kolor stali; szaroniebieski, niekiedy z metalowym połyskiem' (PSWP, 40: 163); 'mający kolor stali, szaroniebieski, czasem z metalicznym połyskiem' (SJPD, 8: 689); 'mający kolor stali; szaroniebieski' (SWJP, 2: 1055). Такое понимание колоратива идет вразрез с данными респондентов. В подавляющем большинстве они признали цвет stalowy оттенком цвета szary (серый). Лишь незначительная часть респондентов указала на доминанту niebieski. По нашему мнению, данный колоратив правильнее определить как 'mający kolor stali; szary z niebieskawym odcieniem'.

Различия между обоими языками выявляются также в группе колоративов, образованных от существительных с непредметным значением. Например, некоторые различия обнаруживаются между польским ochronny и русским защитный. БТСРЯ толкует лексему как 'серовато-зеленый с коричневым оттенком' (БТСРЯ, 359). В польском же языке семантика колоратива шире. Конкретное значение зависит непосредственно от изменчивости цвета окружающей природы и ландшафта и, чаще всего, цвета растительности и земли, ср.: 'kolor mundurów i wyposażenia wojskowego podobny do barw występujących $\mathrm{w}$ otoczeniu, służący do zamaskowania obecności wojska lub broni w terenie' (SJPSz, 2: 437). Однако PSWP указывает на цветовую доминанту коричневого цвета, т.е. усматривает сильную связь с цветом земли, ср.: 'w kolorze ochry, tj. żółty, żółto-brunatny' (PSWP, 25: 194). Русский эквивалент, в отличие от польского, помещается словарями чаще всего в доминанту зеленого цвета, напр.: 'серовато-зеленый с коричневым оттенком' (БТСРЯ, 359)21.

В заключение следует отметить, что расхождения в цветовой доминанте колоративов обусловливаются рядом причин. Одной из них является цветовая нестабильность эталона, вызванная различной стадией его развития. Немаловажную роль играет полицветность эталона. В данном случае в качестве доминанты выступает тот или иной фрагмент образца, характеризующийся разным цветом. Различия в катего-

21 Защцитный цвет понимается также как пятнистый, многоцветный оттенок, состоящий из темно-зеленого, серого и коричневого оттенков, которые неразличимы на естественном фоне (имитируют различные бесформенные объекты). 
ризации являются результатом разной конпептуализации цвета. Из всего сказанного вытекает, что границы между цветообозначениями довольно плавны и неустойчивы. Кроме того, с течением времени значения некоторых колоративов претерпевают семантические сдвиги.

\section{Список источников}

БТСРЯ - Большой толковый словарь русского языка, под ред. С.А. Кузнецова, Санкт-Петербург 1998.

КЦ - А.П. Василевич, С.Н. Кузнецова, С.С. Мищенко, Каталог названий ивета в русском языке, Москва 2002.

НСРЯ - Т.Ф. Ефремова, Новый словарь русского языка, Толково-словообразовательный, т. 1-2, Москва 2000.

СРЯ - Словарь русского языка: 84 томах, под ред. А.П. Евгеньевой, Москва 1981-1984.

СЦ - В.К. Харченко, Словарь извета: реальное, потенииальное, авторское. Свыше 4000 слов в 8000 контекстах, Москва 2009.

ТСРЯ - С.И. Ожегов, Н.Ю. Шведова, Толковый словарь русского языка, Москва 1999.

MSJP - Mały stownik języka polskiego, red. E. Sobol, Warszawa 1995.

PSWP - Praktyczny stownik wspótczesnej polszczyzny, red. H. Zgółkowa, t. 1-50, Poznań 1994-2005.

SJPD _ - Stownik języka polskiego, red. W. Doroszewski, t. I-XI, Warszawa 1969_ 1978.

SJPSz - Stownik języka polskiego, red. M. Szymczak, t. 1-3, Warszawa 1978-1981.

SJPBr - Stownik 100 tysięcy potrzebnych stów, red. J. Bralczyk, Warszawa 2005.

SWJP - Stownik wspótczesnego języka polskiego, red. B. Dunaj, Warszawa 1999.

USJP - Uniwersalny słownik jezzyka polskiego, red. S. Dubisz, Warszawa 2006. 
